\title{
Embedded Teaching Mode to Promote Financial Professional Competences
}

\author{
Yuanyuan $\mathrm{Ma}^{1}$ \\ ${ }^{1}$ School of Economics, Shandong Jiaotong Universdity, Jinan, China \\ Correspondence: Yuanyuan Ma, 202, Unit 4, Building 4, Qilu Garden, Dikou Road, Tianqiao District, Jinan, \\ Shandong, China. Tel: 86-138-5314-6989.E-mail: myy_09@163.com
}

Received: February 19, $2014 \quad$ Accepted: March 5, $2014 \quad$ Online Published: April 14, 2014

doi:10.5430/sass.v1n2p21 URL: http://dx.doi.org/10.5430/sass.v1n2p21

\begin{abstract}
With the process of economy globalization and internationalization, the financial education should cultivate more high-quality professionals in line with the social needs. Traditional teaching modes can't fully meet the requirements for talent cultivation. In this study, we analyze the basic framework of the financial professional capacity and the occupational characteristics under current situation. The traditional teaching modes will be broken through building the "embedded" teaching characterized by "student-center" and "competency-base" modes. The new teaching mode embeds the values, professional identity, knowledge skills and interpersonal skills into the professional competence training. By adhering to the combination of teaching and self-study, the combination of contents and forms, combining theory and practice, we will achieve to raise the comprehensive qualities of students. The result of the present work implied that the reformed teaching mode could meet the demands for talent more effectively.
\end{abstract}

Keywords: embedded teaching, professional competences, occupational characteristics, teaching mode

\section{Introduction}

Since China adopted the reform and opening-up policy in late 1978, financial education has been getting rapid development. Education levels cover the higher vocational education, bachelor, master and doctor. By the end of 2012, enrolled undergraduate students has reached 1.22 million. The elitist education has turned into public education. And yet, there is no denying that the contradiction between the dwindling demands and the increasing enrolment has become more and more serious. It is imperative for educators to ensure that high quality financial talents should satisfy the social request. Beginning with analyzing financial professional characteristics, the purpose of this study is to explore how to adapt, adjust and improve the training mode of professional competence.

Therefore, the reform of traditional financial teaching modes must be enforced. It is urgent to build a "student-center", "competency-based" and "embedded" teaching mode. The embedded teaching mode is to develop professional competence, which is the educational core. Teaching activities, as an organic whole, embed the comprehensive quality in the whole training of professional competence. As far as financial education is concerned, professional education combines financial expertise with moral qualities, cultural qualities and human qualities to improve students' financial professional competences. To meet the needs of society, the "embedded" teaching mode highlights the status of the student through improving their capacities. Traditional teaching mode will be innovated and reformed to reach the application-oriented education goal.

\section{Basic Framework for the Financial Professional Competence}

It takes a long time to perfect professional competences, which can't be obtained fully through undergraduate education. Just as the president of the California Institute of Technology put, "Basically, who we will cultivate are not only engineers, scientists, but talented persons." Hui L (2010) summarized the professional competence for financial employees should include occupation moral qualities, expertise knowledge, working skills and learning ability. In the light of financial education, the financial professional competence should be basis of in the framework. Basic framework for the financial professional competence composes of the following five parts: values of 
professional identity, professional competences, knowledge skills, interpersonal skills and organizational skills. Among them, values of professional identity are the highest reaches of the framework, otherwise, professional competence is the basis. The logical relationship is shown in Fig.1.

\subsection{Values of Professional Identity}

At the top of the framework, values of professional identity belong to the ideological category. Financial education should cultivate students' moral concept and strengthen the social responsibilities. At the same time, we should pay great attention to cultivate the students' financial emotion and the professional identity. Only devote themselves from heart to a financial professional, can they continue to learn, research and innovate to promote their financial theory and practice.

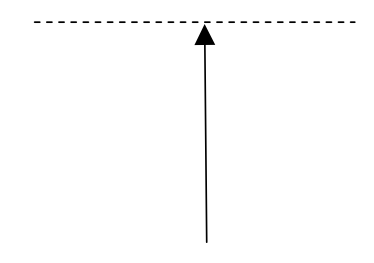

Intellectual factors

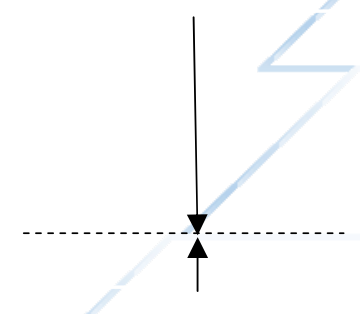

Non-intellectual

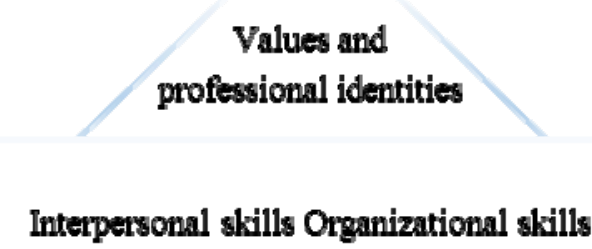

skills of Knowledge

Professional competence

Figure 1. Basic framework for the financial professional competence

\subsection{Professional Competence}

Taken as basic, professional competence refers to the required knowledge and skills to carry out special tasks. The necessary knowledge mainly includes the financial theory and methods, corporate finance, risk management and control, etc. Simultaneously, necessary skills include practical skills, modern information technology. At present, financial education in China should promote professional competence, which is the minimum target of financial education.

\section{3 knowledge Skills}

Skills means the way by which people acquire knowledge including how to obtain and what to get. Knowledge updating grows exponentially with knowledge economy rising and surging ahead every day. Education in school is no longer the "main channel" to acquire knowledge. On the contrary, the major channel for knowledge acquisition is to continue to learn by oneself. Therefore, college education must be changed from accepting knowledge passively into obtaining on one's own. The students has devoted much more efforts to promoting a lifelong learning. Therefore, higher education focuses on training students' ability to learn and capacity of independent construction.

\subsection{Interpersonal Skills}

Financial practitioners should be competent in communication, which means they can transmit their views to the relevant stakeholders timely and accurately to obtain understanding and support. Good communication will get the strong supports and active cooperation in processing financial business. Lack of interpersonal skills and communication ability, financial employees can't be really up to the financial businesses in the future.

\subsection{Organizational Skills}

Businesses become increasingly complex with the speeding up of the transaction innovation. One of the most critical 
requirements for complex business activities is professional judgment. The more complex transactions and business activities are, the higher professional judgment ability will be. In many cases, the complex transactions even depend on team collaboration. As a result, it is essential for the future financial personnel to have the ability of analytical skills, team spirit and innovation ability.

\section{The Changes of Financial Professional Characteristics}

The new circumstances, the new problems and the new contradictions will emerge with the continuous changes in both domestic and international situations, which calls on us to reappraise financial professional characteristics. Accordingly, financial personnel should have much higher professional qualities, which is described below.

\subsection{Weakening the Professional Skills and Strengthening Non-intelligence Factors}

Clients often do with many departments who carry out the following businesses, such as deposits, bank transfer, cash management, financial management, international business services, trust business and investment products. Service quality will be influenced lacking of high moral qualities.

As far as the financial industry is concerned, non-intelligence factors mainly include the teamwork spirit and the vocational moral quality. Due to complexion, financial businesses often need to cooperate with other departments. They will feel unequal to the task without the spirit of teamwork and abilities of communication.

First of all, the diversity of knowledge is necessary to improve financial service. The account managers are responsible for the clients under their jurisdiction when marketing policies involve in agreement. And then all credit approval is related to benefits of all, too. For example, the educational requirements for customer managers are high in Citibank, ranging from at least a bachelor's degree majoring in finance, business administration and marketing to at least other professional postgraduate and MBA (accounting or finance). Secondly, comprehensive service should be provided, too. Each manager must be familiar with their own bank products and services in running the day-to-day operation firstly. High profit depends on good marketing techniques. At the same time, the available abilities to harness high-tech, process information, treat with emergency and apply the financial law is necessary too. Only in this way, can the financial institutes provide unsurpassed quality and services which are the essential guarantees to realize a profit and expand financial transactions.

\subsection{Requiring Comprehensive Quality}

As human science, financial development depends on politics, economy, legal, regime, education, culture and other social factors. Financial environments usually vary with many of the social factors. Mishkin argued that financial intermediation is an important activity in the economy. Effective financial instruments would reduce the transaction costs. Financial transactions could solve adverse selections and moral hazards caused by the information asymmetry. All kinds of savers and borrowers can benefit from the financial markets. And then the economic development becomes more dynamic. In this sense, financial institutions should be the central marketplace of knowledge and information in the society.

Only possess a relatively wide range of knowledge, can financial professionals choose suitable types of assets, acquire revenues and avoid risk for the clients. They need not only learn related subjects such as economics, management, finance and law knowledge, but master the dynamic financial disciplines. In addition, it's best to understand and grasp the necessary relations among the finance and politics, economics, culture and other social factors.

\subsection{Internationalized Vision}

Finance is the general commercial language in international businesses. Under the background of economic globalization, financial internationalization is inevitable. On the one hand, financial personnel should master their own financial standards and application. On the other hand, they should learn international advanced financial theories and practices to keep up with demands of the situation and development. Financial personnel are not the bankers or the analysts indulging in a corner, but the open career which has the international field of vision.

\section{The Main Ways to Implement Embedded Teaching Mode for Financial Professionals}

As has been said, the goal of higher education has changed from elite education to public education in China. In addition, talents who have solid professional theory, profound scientific ability and comprehensive accomplishments have found favor with market demand. In view of social expectations, professional education should be reinforced to 
meet the demands of the times. Embedded teaching focuses on comprehensiveness according to financial professional characteristics and their variations. We may increase humanistic quality curriculums, while strengthening the capacity of financial professionals. Comprehensive quality cultivation is applied throughout the teaching process to promote the overall development of students. To enhance students' professional ability of financial professionals, the strategies are as the following in implementing the "embedded" teaching.

\subsection{Combination of Teaching and Self- learning to Strengthen Interactive Teaching}

Instruction and learning are not detached but are two sides of a coin, which is an interactive bilateral activity between instructors' teaching and students' learning. The quality of financial professionals in teaching can be improved only when effective "teaching" and effective "learning" are ideally harmonized.

First of all, as far as teaching is concerned, financial professional curriculum system should be improved. The sound curriculum system is not only the guarantee for the implementation of embedded teaching mode, but also the premise of improving teaching standards in financial profession. The financial professional curriculums should be in line with market demands and industrial structure adjustment, because social demand act as the driving force. Accordingly, the structure of financial professionals must have their own comprehensive advantages.

To begin with, "demanding". According to changes and demands of financial career, higher education restructures and adjusts the curriculums so as to match market demand. "Practice" is the next. Consistently placing the students' practice ability in a prominent position, the "embedded" teaching implements module teaching to promote integration of theory and practice, which aims to enhance the practical ability and innovative ability. The third is "integration". In terms of curriculum design, natural sciences would be combined with humanity curricula, and foundation courses should coordinate with professional curriculum. Reasonable ratio and structure are considered in order to improve the students' overall quality. The last is "comprehensive". The curriculums of humanism quality are embedded the teaching program while strengthening the financial professional of students.

Secondly, for students' self-learning, teachers should focus on the implementation of interactive teaching through stimulating their initiative, enthusiasm and creativity. In detail, we should give full play to both teachers and students who will establish a teaching mode of democracy and innovation. Focusing on individual development, the sense of cooperation aims at forming the education concept that students are the hosts, and teacher are as guides. In the process, the teaching idea will guide students to change learning behaviors, and establish the new concepts of lifelong learning, autonomous learning, cooperative learning and inquiry learning. On the other hand, we must strengthen the subjective consciousness to maximize the main role of students in teaching. By guiding students to be used to thinking and innovation, the educators encourage students to put forward different views in processing of observation, operation, discussion and questioning. Cultivation of individual talents requires that teaching should break with tradition.

\subsection{Combination of Contents and Forms to Make Professionals Teaching Scientific}

The professional teachers will take it upon themselves to improve the quality and of financial professionals teaching. In detail, they make contents and methods merge with each other and reach perfect unity depending on the course content.

For one thing, teachers should thoroughly research teaching contents and become familiar with the teaching materials so as to analyze professional disciplines. And then they adjust teaching resources if necessary to make the best use of textbooks.

For another thing, the teachers innovate the teaching methods to according to the students' age characteristics, learning interest and learning attitude, etc. In methods, flexible teaching methods, such as, interactive teaching, extra-curricular activities, analysis of case, thematic education, would be carried out to stimulate student's activeness. On the means, the advanced teaching methods are emerging in an endless stream. Network technology, online teaching, multimedia technology can all make the teaching content specific, visualized and vivid. Not only can the students grasp a deep understanding of the knowledge, but the teaching effectiveness is realized, too.

\subsection{Combination of Theory and Practice Enhance Professionals Teaching Effective}

The purpose of learning is to practice and apply. The financial professional curricula are more operational, and need to extend the practice to teaching (Xiaofeng Peng, 2011). To strengthen quality in practice, the professional teachers should combine theory and practice and guide students to pay attention to practice. To be specific, based on the demand characteristics of the financial professional, the experimental design of the curricula should integrate financial data, basic theory and quantitative method. The structure is given in Figure 2. Besides, practice forms may 
be varied with different educational stages, for example, "base practices", "post "practices" and "social practices", etc.

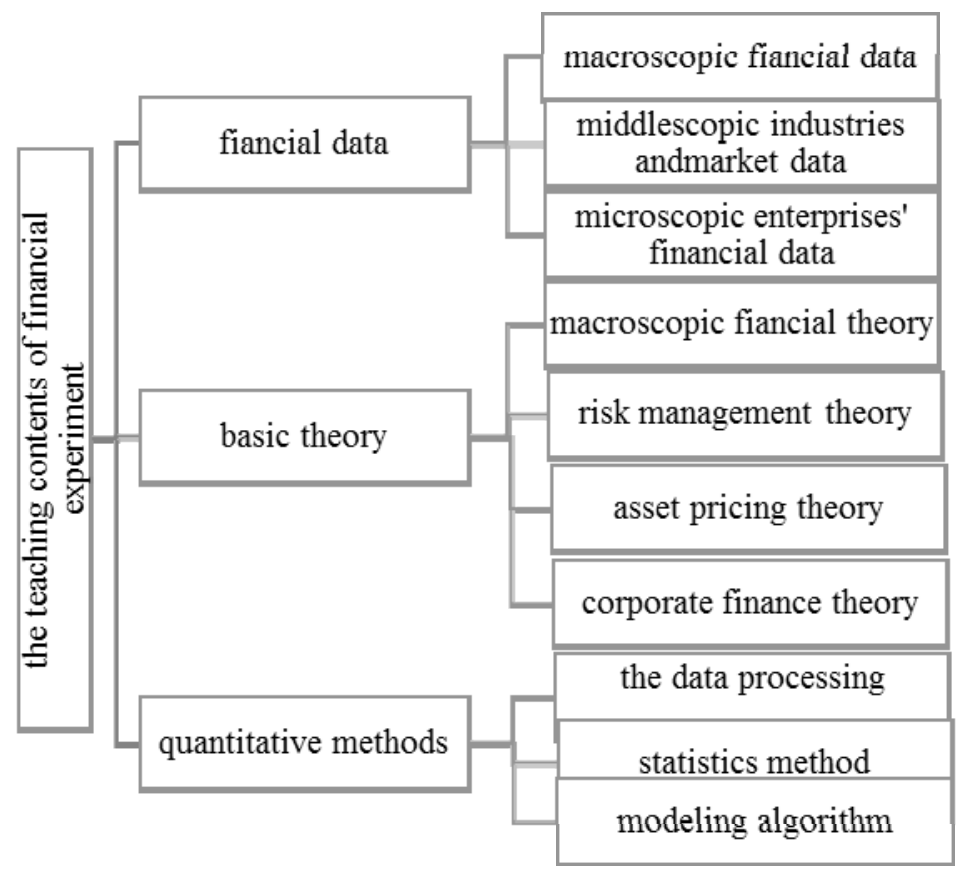

Figure 2. The teaching framework of the financial experimental design

\subsection{Establish a Win-win Pattern Based on Cooperation between Colleges and Enterprises}

We can't improve the quality of financial professional personnel training without the participation and support of the enterprises. In order to improve their cooperation, strengthening and harmonizing relations between colleges and enterprises is a task which brooks no delay. Firstly, providing a platform for them is necessary. When conditions are ripe, we actively introduce enterprises' resources such as capital, technology and equipment to construct training bases. Striving for supports from government, the colleges focus on building a batch of high level training practice bases. The practice bases have the twofold functions. One is the incubator to cultivate students' innovation, and another is the carrier to improve enterprise development.

Next is to innovate university-enterprise cooperation mode. How to design post practice technically, arrange it reasonably, organize it well and manage it specifically is the key point to improve the students' financial professional competence. Supported by practice bases, the industry, the businesses and the professional spirits are built into campus culture, which is benefit for cultivating students' financial professional consciousness. Considering social needs, new personnel training mode, such as "Order" cultivating patter, would link up the professional curriculums with the professional standards. Accordingly, financial professional education are more targeted, flexible and open.

\section{Conclusion}

With the challenge of knowledge economy era, the functions of finance are not confined to the simply medium or financing activities, but a leading and knowledge-intensive industries. Catering to the needs of industrialization, electronic changes and globalization, financial education sets higher standards for the professional talents. On the ground of the severe competition among financial institutions, the professional competences are as follows: good occupation ethics, solid professional skills, broad knowledge, strong learning, adaptive flexibility, foreign languages and public relations. The implement of "embedded" teaching mode implants comprehensive qualities cultivation in the entire process of professional competence to make financial education as organic whole. We will deepen reform of the teaching methods to convey the excellent talents to the society. 


\section{Acknowledgement}

This paper is sponsored by the project "A research on the capability measure-based reform curriculum group -taking Securities Investment for example" from Shandong Province Department of Education.

\section{References}

Albrecht W., \& Sack R. (2000). Accounting Education: Charting the Course through a Perilous Future. American Accounting Association, 203.

Chen L., Chao L., \& Jianjun J. (2002). Research on knowledge ability structure of modern finance professionals. Shaanxi RTVU Journal, 3, 81-88.

Da H. (2001). The "Methodology" Research on Finance discussion Finance. Economic Review, 3, 55-60.

Hui W. (2010). Research on accounting professional ability and "embedded" teaching mode. Communication of Finance and Accounting, 2010(10), 38-41.

IEP2. (2003). Towards Competent Professional Accounts. Retrieved from www.ifac.org

Therdsak Maitaouthong, \& Kulthida Tuamsuk. (2011). Development of the instructional mode by integrating information literacy in the class learning and teaching processes. Education for information, 28, 137-150.

Thomas P. Mackey, \& Trudi E. Jacobson. (2004). Integrating information literacy in lower-and upper-level courses: developing scalable modes for higher education. The journal of general education, 53, 201.

Xiaohui L. (2009). Study on the System of Accounting Teaching: Lessons from the United Kingdom University. Accounting Research, 10, 77-83.

Yan X. (2013). Improving the Teaching Approaches for Accounting Fundamentals by Professional Capacity Building. Journal of Shanxi Finance and Economics University, 09, 71-75.

Yanyan Z. (2013). Research Review on Instructional Mode by Integrating Information Literacy in the Class Learning and Teaching Process. Library Tribune, 3, 178-183 